\title{
Pragmatic multi-scale and multi-physics analysis of Charles Bridge in Prague
}

\author{
Jan Zeman ${ }^{a, *}$, Jan Novák ${ }^{a, b}$, \\ Michal Šejnoha ${ }^{a, b}$ and Jiří Šejnoha ${ }^{b}$ \\ ${ }^{a}$ Department of Mechanics, Faculty of Civil Engineering, Czech Technical \\ University in Prague, \\ Thákurova 7, 16629 Prague 6, Czech Republic \\ ${ }^{\mathrm{b}}$ Centre for Integrated Design of Advanced Structures, Thákurova 7, 16629 \\ Prague 6, Czech Republic
}

\begin{abstract}
Charles Bridge in Prague is one of the most famous monuments of the European architectural heritage. As typical of complex historical structures, a realistic quantitative computational assessment of the bridge response should address multi-physics, multi-scale, time-dependent and three-dimensional aspects of the problem. In this paper, an example of such a study is reported. To keep the model complexity manageable, the analysis is executed in a fully-uncoupled format, where the outputs of individual simplified sub-problems concerning mainly transport phenomena serve as inputs for the dominant part: detailed non-linear three-dimensional and mechanicsoriented simulations of selected bridge segments. The obtained results not only provide the basis for reconstruction works currently in progress, but also demonstrate the applicability and limitations of multi-scale and multi-physics paradigms when faced with complex practical engineering problems.
\end{abstract}

Key words: Historical structures, Multi-scale analysis, Multi-physics phenomena, Computational homogenization, Thermal effects, Transient analysis,

Rehabilitation and restoration

* Corresponding author. Tel.: +420-2-2435-4482; fax +420-2-2431-0775

Email addresses: zemanj@cml.fsv.cvut.cz (Jan Zeman),

novakj@cml.fsv.cvut.cz (Jan Novák), sejnom@fsv.cvut.cz (Michal Šejnoha), sejnoha@fsv.cvut.cz (Jiří Šejnoha).

URL: http://cml.fsv.cvut.cz/ zemanj (Jan Zeman). 


\section{Introduction}

Charles Bridge in Prague is considered to be one of the listed and paramount European historical structures. On 9th July 1357 in the morning, exactly at 5 o'clock and 31 minutes, which corresponds to the palindromic sequence 135797531, Charles IV of the Louxenbourg Dynasty, King of Bohemia, Germany and Italy and Holy Roman Emperor, laid the foundation stone and entrusted Peter Parlér and his stone mason's workshop to put up the bridge. The bridge itself was completed almost fifty years later in 1406. Since that time, it has suffered several havocs, mainly due to repeated floods and water erosion. These were followed by periodic reconstruction, rehabilitation and strengthening measures (see Table 1 for a brief summary of the most important events) which resulted in a large variability of materials as well as construction technologies exhibited by individual parts of the bridge.

The latest chapter in the bridge construction history started in 1994, when a major renovation project aimed at the restoration of the load-bearing capacity and stability of the bridge was launched. In the following decade, the bridge was subject to an extensive experimental in-situ investigation, covering mineralogical and petrographical analyses, chemical and biochemical degradation processes as well as monitoring of temperature and moisture fields in the structure, see [1,2] for a detailed overview of obtained results. In 1997, the authors of the study released the final concept of a large scale repair. In particular, it was claimed that the structure was close to a critical state, predominantly as a consequence of the 1966-1975 reconstruction (recall Table 1), during which new pavement layers and a reinforced concrete slab were built into the structure and the bridge infill was strengthened by high-pressure grouting.

Since then, a vivid discussion of different groups of specialists has been underway on the suitability and necessity of the adopted concept of the bridge repair. An important impulse to the debate was a severe August 2002 flood, which the bridge sustained without notable damage. Moreover, it turned out that despite a noteworthy experimental effort, the computational assessment of the bridge was based on the assumptions of linear elasticity and dimensionally reduced models, e.g. $[1,2,3,4]$. This naturally led to the requirement for more detailed and realistic simulations of the bridge response to relevant external impacts to provide a firmer ground for re-evaluation of the proposed reconstruction measures. The present paper summarizes the results of such a computational study.

There is no doubt that the repair of Charles Bridge is extremely demanding professionally, and, besides, carefully watched by the technical community and public authorities. Therefore, it is perfectly natural that the final conclu- 
sion should be reached on the basis of cogent material models and progressive computational procedures. Of course, as typical of the analysis of complex historical structures, a certain compromise, based on a careful engineering judgement, must be made between the theoretical appeal for the computational model and necessary simplifications due to limited data available; see e.g. $[5,6,7]$ for an excellent survey of this subject. Even under these limitations, recent studies $[8,9,10,11,12,13]$ clearly demonstrate that advanced computational instruments and fully three-dimensional models can provide a reliable tool for diagnostics of historical structures as well as possible remedial measures, especially when compared with simplified approaches based on linear elasticity.

In order to cover the most relevant situations resulting from reconstruction works and the effects of potential floods, a well-founded computational analysis of Charles Bridge should realistically address the structure's response to at least the following external actions:

- self-weight of the structure,

- loading due to spatially and temporarily varying temperature changes,

- water pressure including possible uplift,

- floating vessel impact,

- effects of heavy machinery used to remove debris during floods,

- conservative estimate of the load-carrying capacity of the bridge.

Strictly speaking, the above-mentioned requirements indicate that the "utopia" analysis to be performed should be:

- multi-scale in time and space due to the heterogeneity of the structure on several levels of resolution,

- based on non-linear material models taking into account quasi-brittle response typical of masonry,

- multi-physical to incorporate climatic effects on the structure as well as interaction of the bridge with water,

- three-dimensional as the bridge is a very massive structure and hence dimensionally reduced models cannot be applied,

- transient to properly describe inertia effects due to bridge-vessel collision and to cover the behaviour of the bridge in different parts of the year.

Nevertheless, despite the significant progress in strong coupling procedures for multi-physics and multi-scale phenomena in recent decades $[14,15]$, such a fully-coupled analysis is currently not feasible, not only in terms of viewpoint of numerical and implementation difficulties associated with the treatment of the complex three-dimensional problem, but mainly due to the lack of reliable data to describe the interaction mechanisms. Therefore, the pragmatic engineering approach adopted in this work is to "decouple" the analysis into 
several independent simplified components, which are solved separately using specialized codes. The outputs of these sub-problems then serve as inputs for the main part of the analysis: a macroscopic non-linear mechanical simulation, with material constants derived from meso-scale simulations, allowing us to assess their impact on the overall behaviour of the bridge.

Following this strategy, the paper is organized as follows. In Section 2, a threedimensional CAD model of selected portions of the bridge is introduced and converted to a tetrahedral finite element mesh. The first-order homogenization techniques used to determine the effective material parameters are discussed in Section 3; Section 4 summarizes the computational procedures employed to quantify the effects of external actions. Validation of the numerical model against available experimental data is presented in Section 5, followed in Section 6 by the computer-aided assessment of the current state of the bridge. Finally, concluding remarks towards practical implications of the performed analysis and future extensions are presented in Section 7.

\section{Geometrical model of the structure and boundary data}

\subsection{Brief characterization of the bridge}

Charles Bridge links both banks of the Vltava River in Prague and, even in present days, serves as an important connection between the Old Town and the Lesser Quarter. The bridge is decorated by a unique alley of 31 statues and statuettes, most of them baroque-styled. The bridge body is slightly S-shaped in a ground plan, 516.7 meters long and 9.1 to 9.7 meters wide, resting on fifteen arches with a span ranging from 16.6 to 23.4 meters, cf. Fig. 1(a). The bridge is supported by sixteen massive piers with a cross-section of 6.3 to 10.8 meters wide and a height varying from 24 to 25 meters, originally founded on millstones either supported by oaken grillages or boxes anchored to the bed of the river. The authentic foundations were gradually replaced or strengthened during remedial measures: in the 1902-1903 period, piers 3,4 and 7 were rebuilt on a concrete slab resting on seven caissons of 2.5 meters in diameter while piers 5 and 6 were founded on a vault supported by two six-meter caissons during the 1892 reconstruction (recall Table 1). The subsoil is formed by a rock massif consisting of Ordovic shales and quartzite (showing almost no surface erosion), covered by a 5 to 10 meter thick layer of coarse-grained gravel with the particle size of up to 0.5 meters. 


\subsection{Volumetric and computational models}

The basic data used as a point of departure for the construction of the structure's geometrical models were provided by a detailed three-dimensional surface representation acquired during the previous photogrammetric survey [16]. In the next step, to (at least partially) reproduce the complex heterogeneous structural system, the bridge body was partitioned into several quasi-homogeneous parts. They correspond to different materials appearing in the structure, including a detailed representation of pavement layers. The model was completed by adding volumes representing the gravel layer and the rock massif. An exploded view of the resulting CAD representation is shown in Fig. 2.

Two models of bridge segments with a different level of details were considered in the numerical analysis. The first variant involved arches No. III and IV with the maximum distance between the supports, see Fig. 1(a), and incorporates all the details of the CAD model. The two-span segment (referred to as variant $\mathrm{A}$ in the sequel) was introduced to provide an insight into dominant interaction mechanisms and the resulting damage states for the relevant external actions. The second, six-span segment (model B), was essentially aimed at estimating the load bearing capacity of the bridge and the subsoil during the reconstruction works. Model B captures the behaviour of arches No. II-VII and includes the Velflik arches introduced into the structure during the 1903 reconstruction, recall Table 1 and Fig. 1(a). Unlike the first variant, the latter model omits the details of the pavement structure and lumps individual layers into one object. Such a simplification has a negligible effect on the global response of the bridge while keeping the problem size manageable.

The last step of the geometrical modelling involved the discretization of both CAD representations using the T3D mesh generator [17]. The resulting tetrahedral element meshes, displayed in Fig. 3, consist of 97, 004 tetrahedral elements and 20,409 nodes for the two-span variant and 31,725 nodes connected by 142, 976 elements for the six-span segment, respectively. Clearly, the resolution of model $\mathrm{A}$ is considerably higher when compared to model $\mathrm{B}$, mainly due to the mesh refinement in the vicinity of the boundary and internal interfaces.

\subsection{Specification of boundary data}

When creating a realistic computational model, an important point is the correct specification of boundary data. In all reported simulations of the mechanical response, the Dirichlet boundary conditions were applied at the base of the model and, in order to approximate the collective effect of the remaining 
segments of the bridge, the conditions of periodicity were prescribed to the homologous surfaces. Moreover, a perfect bonding between individual quasihomogeneous parts was assumed since the quality of the interfacial region is almost impossible to characterize [2] and the deterioration of the material in the vicinity of internal interfaces is accounted for by the adopted constitutive description.

\section{Material parameters}

As discussed in the introductory Section, the bridge body is strongly heterogeneous on several lenghtscales. While specific parts of the structure can be characterized as macroscopically homogeneous, e.g. a reinforced concrete slab, pavement layers or subsoil, various types of masonry forming the bulk of the structure can only be treated as homogeneous on the mesoscopic level (i.e. on the scale of individual constituents). In particular, (at least) three distinct mesoscopic heterogeneity patterns can be distinguished in the bridge body, see Fig. 4:

- regular periodic sandstone facing of vaults,

- sandstone masonry with a non-periodic arrangement of blocks used in the facing of breast walls,

- filling irregular quarry masonry consisting of arenaceous marl blocks and mortar made of sand and black lime.

The constitutive models employed to represent the mechanical behaviour of individual quasi-homogeneous units for structural assessment are summarized in Fig. 2. The most critical regions of the structure were modelled using a quasi-brittle constitutive law briefly summarized in Section 3.1, while for the remaining units, an isotropic linear elasticity was assumed. Summary of available experimental data related to the determination of properties of individual constituents is gathered in Section 3.2 to provide a basis for characterization of the overall behaviour of masonry using the first-order homogenization in Section 3.3. It is worth noting that such an approach is rather universal, as illustrated by a complementary analysis of the heat transfer phenomena also reported below.

\subsection{Material models}

The non-linear mechanical behaviour of masonry, concrete and selected layers of pavement was modelled using the CC3DNonLinCementitious plasticfracturing constitutive model available in the ATENA 3D system [18]. The 
model is formulated in the total format, assumes small strains and the initial isotropy of a material. The tensile behaviour is governed by the Rankinetype criterion with exponential softening while in compression, the MenétreyWillam yield surface with hardening and softening phases is used. The fracture model employs the orthotropic smeared crack formulation and the fixed crack model with the mesh adjusted softening modulus. This model is defined on the basis of characteristic element dimensions in tension and compression, to ensure the objectivity in the strain-softening regime. A specific material is described using five well-defined input parameters: tensile and compressive strengths $f_{t}$ and $f_{c}$, Young's modulus $E$, Poisson's ratio $\nu$, the fracture energy $G_{f}$ and the limit compressive crack opening $w_{d}$, see Fig. 5(b) and Table 2 for illustration. Additional details of the model formulation are available in $[18,19,20]$. In all mechanical simulations, low-order discretization of displacement fields was employed to keep simulations manageable: bi-linear four-node elements with four-point integration scheme for two-dimensional analyses and linear tetrahedral elements with one-point integration scheme for three-dimensional problems were employed.

The constitutive description employed for the analysis of coupled heat and moisture transfer treats individual materials as porous media described by the Künzel diffusion model [21]. The theoretical description is based on the simultaneous balance of heat and moisture formulated in terms of the relative humidity $\varphi$ and temperature $T$ as unknown field variables. The dominant parameters describing a particular material include the density $\rho$, thermal parameters (thermal conductivity $\lambda$ and heat capacity $c$ ) and hygric data defined on the basis of sorption isotherms, see [21] and [22, Section 3.2.3] for further details, and Fig. 6(a) for illustration. The temperature- and moisturedependent parameters of the constituents were determined from the extensive material database available in the DELPHIN code [23] and supplementary measurements reported in [24]. Note that in accordance with the adopted fullyuncoupled approach, the transport problems were solved independently of mechanical analyses; the only one-way thermo-mechanical coupling considered was induced by the effective thermal expansion coefficient.

\subsection{Brief summary of available experimental results}

During the 1994-2004 period, an extensive study on mechanical properties of the dominant components of the bridge was launched, see $[1,2,25$, and references therein]. A total of twelve dug holes with diameter of $137 \mathrm{~mm}$, covering the whole bridge body, were used to obtain samples of sandstone blocks, aranceous marl backfill, black lime mortar, reinforced concrete slab and pavement layers. 
The experimental characterization involved the measurement of the static Young modulus and Poisson ratio, dynamic Young modulus determined from ultrasonic measurements, compressive and tensile strengths and fracture energy determined from the three-point bending tests. In addition to the drystate compressive strength, tests under the fully saturated conditions were executed to quantify the moisture-induced reductions of mechanical data. The constants used in the following analysis correspond to the mean values determined from at least three samples.

\subsection{Virtual testing via computational homogenization}

Using traditional approaches, a direct constitutive characterization of each masonry configuration introduced in Fig. 4 would require a large-scale destructive experimental program [2], which is nevertheless not feasible due to economy and historical heritage conservation constraints. In this regard, computational homogenization methods offer a particularly convenient opportunity allowing for a substantial reduction of the number of in-situ tests. The strategy employed in this work is based on the well-established first-order homogenization schemes, e.g. $[26,27,28]$. In this framework, each heterogeneity pattern is characterized by a statistically equivalent periodic unit cell [29], which is subject to a prescribed loading history parametrized by the macroscopic strain tensor $\boldsymbol{E}$. The influence of the surrounding material is again accounted for by using periodic boundary conditions, now imposed on the boundary of a unit cell. The effective (homogenized) material behaviour is deduced from the relation between the overall strain and the corresponding average stress $\Sigma$ in the unit cell, typically specified in the form of uniaxial stress-stress relations or failure envelopes, e.g. [30,31, and references therein].

Consider, for example, a unit cell corresponding to the regular masonry pattern shown in Figs. 4(a) and 5(a). In the analysis, both constituents were modelled as quasi-brittle and the plane strain state was assumed. The Mohr-Coulomb interfacial element, characterized by the cohesion $c$, the angle of internal friction $\phi$ and the tensile strength cut-off $f_{t}$, was used to simulate an imperfect bond between bricks and mortar. The elastic constants of the material model as well as the compressive and tensile strengths were determined directly from a simulated uni-axial loading by the overall strain applied in the planes of the material orthotropy; the macroscopic fracture energy was estimated by a novel procedure derived from the RILEM work-of-fracture method [32]. In order to incorporate, at least to some extent, the initial and damage-induced anisotropy typical of masonry, the parameters used in the macroscale simulations were set to the geometrical averages of the values obtained in the two directions. The results of the homogenized mechanical parameters for the regular masonry facing are stored in Table 2 and a sketch of the corresponding macro- 
scopic stress-strain law is plotted in Fig. 5(b) using equivalent stresses and strains, e.g. [33]. Additional details of the procedure including a numericalexperimental verification can be found in the accompanying paper [32].

Note that the non-periodic and irregular quarry masonry patterns, recall Fig. 4(b,c), were treated on the same footing employing the concept of a Statistically Equivalent Periodic Unit Cell, which approximates a non-periodic masonry texture with a Periodic Unit Cell sharing the same statistical response with the original sample, see [29] for further discussion.

As demonstrated by previous in-situ studies [1,25,34], selected parts of the bridge show an increase moisture level, which, in turn, results in the reduction of the overall mechanical properties. In general, a rigorous quantification of such an effect would require a detailed moisture-damage simulation, executed in a fully coupled format, cf. [35,36,37, and references therein]. This subject, however, remain to be highly complicated and as such goes far beyond the present scope of macroscale engineering analysis. Therefore, in the adopted fully uncoupled framework, a simple experimental-based reduction has been adopted. In particular, the obtained dry-state macroscopic data were set to $80 \%$ of their original values, which corresponds to the maximum decrease observed experimentally in [25] for sandstone samples under the fully saturated conditions.

A completely analogous procedure was executed for the homogenization of transport parameters, with a special emphasis given to the correct treatment of the heat transfer phenomena. Following the mechanical homogenization procedure, the macroscopic thermal conductivities for individual types of masonry follow from the average value of the steady-state heat flux resulting from the prescribed macroscopic temperature gradient applied to orthogonal directions. The remaining hygric and thermal parameters were estimated as the volumetric averages of the data related to individual constituents, see [38,39] for more details and Table 2 and Fig. 6(a) for a specific example. Note that due to simultaneous heat and moisture transfer, the homogenized thermal conductivity consistently incorporates the effect of the increased moisture level in the bridge body. In particular, it can be observed that the homogenized conductivities remain roughly constant in the range $\varphi \approx 15 \div 40 \%$ measured in [34] and are independent of the temperature gradient [39]. When compared with the homogenized mechanical behaviour, it can be seen that the effective transport properties almost duplicate the data for the sandstone block. This can be primarily attributed to the assumption of the temperature continuity across the interfaces, adopted due to the lack of experimental characterization, see [39] for further details. Such results provide an essential ingredient for the estimate of the spatial distribution of temperature, cf. Section 4.2.

The final simulations carried out on the mesoscale level were aimed at quanti- 
fying the thermo-mechanical coupling in terms of the homogenized coefficient of the thermal expansion $\alpha^{*}$. To that end, each representative volume element was subject to a uniform negative temperature change $\Delta T$, while setting the overall mechanical strain to zero. Fig. 6(b) shows the plots of the resulting equivalent macroscopic stress $\Sigma_{\text {eq }}$ together with the associated reduction of the effective thermal expansion coefficient from the initial value $\alpha=12 \cdot 10^{-6} \mathrm{~K}^{-1}$, cf. Table 3. Evidently, under macroscopically fully constrained conditions, even for a moderate temperature change the homogenized thermal expansion coefficient reaches almost a zero value due to extensive cracking. Nevertheless, to reflect an approximate character of the adopted assumptions, a conservative value $\alpha^{*}=7 \cdot 10^{-6} \mathrm{~K}^{-1}$ (corresponding to the temperature change $\Delta T \approx-3^{\circ} \mathrm{C}$ ) was employed in the macroscale analysis. It is noteworthy that such a value compares rather well with $\alpha^{*}=8 \cdot 10^{-6} \mathrm{~K}^{-1}$ reported independently in [2].

\section{External actions}

Nowadays, when the bridge is accessible to pedestrians only, the dominant actions on the structure result from the self-weight, temperature changes in the course of the year and water pressure. In addition, a simplified model was considered to account for inertia effects arising due to a possible ship impact during a flood. To provide reliable estimates of the selected loading conditions, each of them was determined from an independent analysis and, when applicable, validated against data available in open literature.

\subsection{Self-weight}

Due to the massive character of the structure, self-weight presents by far the most dominant permanent action. Even more importantly, it turned out that the definition of the computational model could play a central role in arriving at a truly predictive model. In the macroscopic analysis, the self-weight load was applied to the structure independently, prior to the introduction of all remaining external actions. If the self-weight was applied to the structure in a single step, i.e. directly to the model Fig. 7(c), even the results of the linear elastic analysis predicted the appearance of excessive tensile stresses in the bridge vaults, indicating the global collapse of the bridge already during the construction stage. When adopting a more realistic scenario, when three distinct stages of construction were considered and the self-weight was applied incrementally, cf. Fig. 7(a-c), the refined model showed a meaningful distribution of stresses as well as distributed cracking patterns. 


\subsection{Temperature analysis}

In its full generality, the determination of a spatial and temporal distribution of temperature changes in the bridge body would involve three-dimensional non-stationary coupled heat and moisture transfer with non-linear material properties and site-specific climatic boundary data. Such a simulation, however, would be beyond the available computational resources. Therefore, only a two-dimensional cross-section of the bridge segment located at the mid-span of arch No. X, see Fig. 8, was subject to a non-stationary analysis. Such a simplification not only leads to a significant reduction in the problem size, but also facilitates the use of the specialized Finite Volumes code DELPHIN [23] for the intended simulation.

In the reported study, the distribution of temperature and moisture fields in the cross-section was determined for a ten-month period starting from April of a typical year. The boundary conditions employed in the analysis were determined from representative Prague climatic data [24] and include the effect of sun radiation, wind, rain, heat convection and the structure's orientation. The initial distribution of temperatures and relative humidity were set to the average annual values. Fig. 9 shows the distribution of daily maximum and minimum temperature during the reported period in the selected monitoring points. It can be obseved that, after a period of approximately one month affected by the initial conditions, the temperature values follow the annual cycle and vary from -14 to $45^{\circ} \mathrm{C}$.

To validate the simulation results, the extreme values determined for the second week of July and the last week of November are compared with in-situ measurements performed in 1989, see [40]. As demonstrated by Table 4, the simulation results are in a rather good match with the experimental data, especially when taking into account the adopted simplifications and the oscillatory character of daily extremes in the winter period, recall again Fig. 9(b).

Among other things, the numerical simulation demonstrated that the temperature variation was confined to layers close to the boundary while the temperature in the bridge interior remained constant in space and varied between $6^{\circ} \mathrm{C}$ and $17^{\circ} \mathrm{C}$. The extreme surface temperatures were extrapolated to $-15^{\circ} \mathrm{C}$ and $52^{\circ} \mathrm{C}$, respectively. Consequently, the three-dimensional temperature field in the structure was analyzed by solving a linear steady-state heat transfer problem (with material parameters predicted by computational homogenization) with the surface and interior temperature set to the values determined from the two-dimensional data. The resulting temperature change profiles, corresponding to the reference temperature equal to the annual average value of $10^{\circ} \mathrm{C}$, are reported in Fig. 10 . 


\subsection{Water pressure}

Following the standard engineering practice [41], both hydrodynamic as well as hydrostatic water pressure components including the uplift, destabilizing the structure in the case of an accidental horizontal action, were taken into account. Two different water levels were considered: one corrersponding to the average annual value and one extreme level, related to the August 2002 flood. In the first case, the water velocity and the hydraulic head were determined from long-term statistics of available hydrological data while the input for the latter case was adopted from the results of the two-dimensional finite element analysis of a dissipative Navier-Stokes flow [42] illustrated in Fig. 11.

\subsection{Impact load}

The final external action considered in the non-linear mechanical model was a tag boat colliding with the bridge during a flood. Due to a rather limited extent of input data (only the weight and dimensions of the boat were provided), we adopted a simple two-degree-of-freedom model to estimate an equivalent static impact force. The scheme of collision is visible from Fig. 12(a) together with the geometrical parameters of the model. Additional inputs were the circular frequency $\omega_{2}$ corresponding to the lowest horizontal transverse eigenmode, the compressive strength of pier masonry $f_{c}$ and the ratio between the compliance of a tag boat $c_{r}$ and that of a pier, estimated as

$$
c_{p} \approx \frac{1}{4 H f_{c}}
$$

where $H$ is the height of the contact area. With these parameters, the equations of motion for the boat-bridge system can be written in the form, see [43] for more details:

$$
\begin{aligned}
\frac{\mathrm{d}^{2} R}{\mathrm{~d} t^{2}}(t)+\omega_{1}^{2} R(t) & =-\frac{1}{c_{r}+c_{p}} \frac{\mathrm{d} u_{2}}{\mathrm{~d} t^{2}}(t), \\
\frac{\mathrm{d} u_{2}}{\mathrm{~d} t^{2}}(t)+\omega_{2}^{2} u_{2}(t) & =\frac{R(t)}{M_{2}}
\end{aligned}
$$

complemented with the initial conditions

$$
\begin{aligned}
& u_{2}(0)=0, \frac{\mathrm{d} u_{2}}{\mathrm{~d} t}(0)=0, \\
& R(0)=0, \frac{\mathrm{d} R}{\mathrm{~d} t}(0)=\frac{v_{r}}{c_{r}+c_{p}},
\end{aligned}
$$


where $v_{r}$ denotes the velocity of the ship determined from the profiles shown in Fig. 11. In Eqs. (2)-(5), $R$ stands for the dynamic impact force; the equivalent circular frequency $\omega_{1}$ was set to

$$
\omega_{1}=\sqrt{\frac{1}{M_{1}\left(c_{r}+c_{p}\right)}} .
$$

The previous system of equations allows us to estimate, for the given input data, the maximum positive contact force $R_{\max }$ occurring during the impact.

In the reported simulation, the relevant natural frequency of the bridge was determined from a linear frequency analysis; the corresponding mode of vibration is shown in Fig. 12(b). The effective vibrating mass of the bridge $M_{2}$ was set equal to the weight of the bridge segment, omitting the negligible influence of the subsoil. The remaining parameters of the model are summarized in Table 5, leaving us with one parameter, the relative bridge compliance, unspecified. The sensitivity of the contact force $R_{\max }$ with respect to the ratio $c_{r} / c_{p}$ is shown in Fig. 12(a), leading to a rather conservative upper bound on the equivalent static contact force $R_{\mathrm{eq}} \approx 14 \mathrm{MN}$, corresponding to $c_{r} / c_{p} \approx 3$. Consequently, this value was used as the input for the mechanical analysis.

Quite surprisingly, the results of such a simple analysis agree remarkably well with an independent study [44], which reports the value of the $99.9 \%$ quantile equal to $13 \mathrm{MN}$ for a geometrically similar historical bridge. In addition, the horizontal character of the first mode shape of the bridge, as opposed to the vertical vibration shape typical of modern structures, is consistent with experimental data available in [45]. This solely provides a partial validation of the proposed simple model since no results of dynamic tests of Charles Bridge are currently available.

\section{Computational model validation}

In view of the numerous approximations and idealizations adopted in the formulation of the computational model, it is obviously necessary to validate the simulation results against available experimental data [2,25]. In the present Section, the predictive capabilities of the model are demonstrated by the comparison of crack widths, damage patterns and displacements of the bridge facing ${ }^{1}$

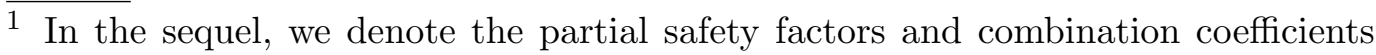
associated with an external action as $\gamma$ and $\psi$, respectively. The symbol $\oplus$ is reserved for the superposition of individual actions appearing in a combination.
} 


\subsection{Current damage state}

According to in-situ observations [2,3], the damage of the structure is mainly localized in the vaults and in selected parts of the parapet walls. The cracks appearing in periodic sandstone masonry are aligned with the $x$ axis and are located approximately at a one-meter distance from the face of the breast walls. Additional extensive cracking is visible in the vicinity of individual statues in buttresses, especially in the obtuse angle corner between the buttress and a straight breast wall. Moreover, several cracks initiate at the mortar joints located at water level and extend to the vaults. The localized damage is accompanied by various minor cracks appearing in the structure, which infers no threat to the structure's stability.

A commonly accepted explanation of the crack development driving mechanism is a non-uniform temperature change of individual bridge parts, leading to the appearance of high shear stress levels. Another dominant effects are the tensile stresses arising due to self-weight located in the cracked area of the bridge vaults. On the other hand, the damage development cannot be attributed to the movement of foundations as all pier footings are now secured to exhibit sufficient stability, recall Table 1.

\subsection{Overview of experimental data}

Two quantities related to the bridge behaviour were monitored on a longterm basis: (i) the displacements of the breast walls, (ii) crack width observed on surfaces of the vaults, cf. [2,3,25]. The displacement-based measurements involved the relative horizontal and vertical displacements of breast walls as well as their tilting, cf. next Section, measured at 34 point distributed uniformly along the bridge. The displacements were determined using laser level with a tolerance $\pm 0.2 \mathrm{~mm}$, whereas for the inclination measurements, a highperformance inclinometer with the angular resolution of $\pm 5^{\prime \prime}$ was employed. The crack opening displacements on the surface of the values were measured using displacement gauges (with the accuracy of $\pm 2 \mu \mathrm{m}$ ) and, independently, using visual gauges with the resolution of $\pm 0.1 \mathrm{~mm}$. The data stored in Table 6 correspond to statistics obtained during the 2003-2004 period.

\subsection{Simulation prediction}

To validate the performance of the model, two representative load combinations were examined. Both cases include self-weight of the structure, water pressure due to the normal water level and the summer and winter tem- 
perature changes, respectively. The resulting crack distributions are visible from Fig. 13. Both results illustrate the dominant character of temperature loading as the crack distribution almost exactly duplicates the non-uniform temperature changes, compare Figs. 10 and 13. Note that this finding is fully consistent with the damage driving mechanism discussed above 2

Moreover, Table 6 shows a quantitative comparison of simulation results and experimental data available from previous studies. In the present case, the values of the crack width stored in Table 6 correspond to the maximum crack opening displacements found on the surface of the two vaults. The numbers in parentheses denote standard deviations. The horizonal and vertical displacements were postprocessed from the simulation results according to the procedure employed in [25] for experimental data: first, for each parapet wall, the displacements of the end points of the upper parapet edges were determined; second, extreme displacements, defined as the difference between the computed values of displacements and the linearly interpolated endpoint data, were determined. The values appearing in Table 6 correspond to the $90 \%$ confidence intervals determined from the data for the four parapet walls. A similar procedure was executed to evaluate the distribution of tilting angles.

Clearly, the values predicted by the model comply very well with the experimental data, especially when taking into account the complex character of the bridge structure. Therefore, it can be safely conjectured that the proposed model correctly captures the main damage processes occuring in the structure and as such it can be used for both the quantitative and qualitative structural assessment.

\section{Computational assessment of Charles Bridge}

The results presented in Section 5 fully confirm the predictive capabilities of the proposed model. Therefore, we proceed to the assessment of the current state of the structure for additional external actions. The reported analyses cover the simulation of temperature cycle effects and the impact of a tag boat, complemented with an estimate of the bridge load-bearing capacity.

\footnotetext{
2 In this context, it is fair to mention that the boundary layer of localized damage appearing in the vicinity of periodic surfaces, see Fig. 13, is a modelling artifact resulting from the boundary conditions which fail to describe the bending mode of the structure. Nevertheless, this inconsistency is highly localized and the employed boundary conditions are less restrictive when compared to other possibilities to ensure the interaction with the remaining parts of the bridge.
} 


\subsection{Effect of temperature cycle}

This load combination incorporated the self-weight, normal water level and the summer-to-winter temperature change, the latter reduced by a combination coefficient. It is obvious from the results shown in Fig. 14 that the collective effect of the temperature cycle results in the closing of previously opened cracks. In comparison with the extreme positive and negative temperature changes, the crack widths are substantially reduced, the only minor deterioration is visible in the foundation regions and, to a limited extent, on the vault surface. The reinforced concrete slab, on the other hand, does not appear to act as an expanding lever, as suggested in $[2,3]$, but rather prevents the tilting of the breast walls due to masonry contraction.

\subsection{Tag boat impact}

This extremal loading combination involves the effects of the self-weight of the structure, water pressure due to a flood (including uplift), extremal summer temperature changes, the impact of a tag boat and the self-weight of a vehicle located at the vault mid-span. Note that due to its stabilizing effect, the selfweight in this case is reduced by the coefficient of combination, which again results in a limited closure of some pre-existing cracks.

Quite surprisingly, even such an unfavorable case does not indicate the global collapse of the bridge. This is documented by Fig. 15(a), showing the distribution of residual tensile strength. There is no visible reduction of the tensile strength in the region of the boat impact, indicated in Fig. 15(b) by the area of compressive stresses $\sigma_{y y}$. The only defects visible in the footings of the piers and on the interface of the structure seem to be due to the temperature change. This again confirms the dominant character of temperature loads on the behaviour of the bridge. Again, the reinforced concrete slab plays a positive role as it uniformly distributes the horizontal stresses within the whole segment. Nevertheless, it can be inferred that if the collision effects are combined with the already present damage concentrated predominanly in the foundations, their interaction with the water flow may lead to the collapse of a part of the bridge.

\subsection{Subsoil load-bearing capacity}

The distribution of the stresses $\sigma_{z z}$ in the subsoil, used for the structural assessment, was based on the analysis of the six-span variant. The analysis results reported in Fig. 16 correspond to the loading due to self-weight of 
the structure and the normal water level. The stress level experienced by the subsoil in the foundation area ranges from $0.3 \mathrm{MPa}$ to $1.5 \mathrm{MPa}$, appearing in the vicinity of the sharp edge of the foundation, which is substantially smaller than a conservative estimate of the subsoil load-bearing capacity of $2.5 \mathrm{MPa}$ taken from [46]. This provides an a-posteriori justification of the linear elastic model, adopted for the subsoil layers, cf. Fig. 2. Therefore, provided that the erosive effect of water, and the pier scouring in particular, is minimized, the reliability of the bridge foundations seems to be sufficient.

\subsection{Estimate of load-bearing capacity}

A proper choice of a procedure for estimating the load-bearing capacity of historical masonry bridges is rather a delicate task. According to the standard approach, e.g. [47], the load carrying capacity is understood as the ratio between the maximum admissible stress and the maximum stress in the structure induced by a 1-ton vehicle. Such a procedure is essentialy based on the validity of linear elasticity, which in the present case is not even met for the dead-load effects. Therefore, the present assessment is performed using the convergence characteristics of the Newton-Raphson iterative procedure as the indicator of the deviation from linearity. Moreover, to obtain a reliable estimate, all the strength and fracture parameters were decreased by the material partial safety factor $\gamma_{M}=2.5$.

For the two-span model A, the loading was induced by an 80 ton four-axle vehicle speficied in [47], excentrically located at the arch mid-span, with a continuously increasing self-weight. The global measure of the bridge stability, expressed in terms of the number of iterations for a given loading step, is shown in Fig. 17. Clearly, the bridge response remains (almost) elastic in the first four iterations; the regime of higher non-linearity was achieved for the weights in the range of $480 \div 560$ tons. Taking into account the uncertainties of the quality of the connection between the breast wall and marl filling, we assessed the load-bearing capacity of the bridge as $4 \times 80=320$ tons, which is more than sufficient for the purpose of the intended reconstruction works.

The results of the two-span model were complemented with the analogous procedure for the six-span variant. In contrast to the former case, the vehicles were located in the region of the Velfik arches, see Fig. 1(a). The corresponding convergence graph, depicted in Fig. 17, shows no marked deviation from linearity during iterations No. $1 \div 37$; while the segment collapses in the next increment. This behaviour can be attributed to the fact that the increasing number of iterations in model $\mathrm{A}$ indicates the failure of pavement layers, which were gathered into one unit for the six-span segment. Therefore, we conjecture that the bridge load-bearing capacity is bounded by the strength of the 
upper layers of the pavement. Finally, to indicate the position of the vehicles, the global failure modes of both models are displayed in Fig. 18. Note that the displacement imcompatibilities, especially pronounced in Fig. 18(a), result from the geometry changes used to apply the self-weight, recall Section 4.1, not the collapse mechanism itself.

\section{Conclusions}

The present contribution presents an overview of an "engineering" multi-scale and multi-physics analysis of Charles Bridge in Prague. To make the simulation feasible, the complex problem has been decomposed into several independent components, which have been used to determine reliable inputs for a three-dimensional non-linear mechanical analysis employed to estimate both the stress and damage states of the structure.

From the theoretical point of view, we have demonstrated that the computational homogenization approaches, when carefully validated with small-scale tests and engineering judgement, can provide a rational procedure for feeding material models with reliable data without a need for large-scale destructive experiments. This conviction has further been supported by the sucessfull validation of the simulation against in-situ observed damage patterns and displacements. Similar conclusions can be drawn from the remaining parts of the analysis describing heat transport phenomena and the impact analysis.

The practical outcomes of the presented analysis are even more important. In particular, it has been demonstrated that the bridge is currently stable and safe for all load combinations both locally as well as globally. From all external actions, the temperature effects have the most pronounced impact on the bridge behaviour. Nevertheless, when taking into account the whole temperature cycle, it can be safely concluded that they do not constitute a significant threat to the bridge stability. From the structural point of view, it seems that the foundations present the most critical parts of the structure. The effect of the reinforced concrete slab, on the other hand, is positive rather than detrimental.

In overall, it can be concluded that the first priority is to restore the functionality of the damp proofing system of the bridge. On the other hand, replacement of the components introduced into the structure during the 1966-1975 reconstruction is not necessary as the load-bearing capacity of the bridge is sufficient and the temperature effects seem to be stabilized. In addition, there is no need to introduce a compliant separation layer between the parapet walls as proposed in $[2,3,4]$; their mutual interaction is prevented by the temperatureinduced cracking, recall Fig. 13. Finally note that these conclusions provided 
the basis for the most recent minor reconstruction works launched in August 2007. Along with the remedial measures, a long-term monitoring system of the bridge is planned to be installed, providing a convenient basis for the future refinement of the existing computational models.

\section{Acknowledgements}

The authors would like to thank Jiří Maděra for a number of intensive discussions and assistance in solving the coupled heat and moisture problems and Tomáš Plachý for drawing our attention to reference [45]. This outcome has been achieved with support from the Ministry of Education, Youth and Sports of the Czech Republic, project No. 1M0579 and the Grant Agency of the Czech Republic, project No. 103/08/1531.

\section{References}

[1] J. Witzany, V. Mencl, R. Wasserbauer, M. Gregerová, P. Pospíšil, T. Čejka, R. Zigler, E. Burgetová, Overall assessment of theoretical and experimental investigation of Charles Bridge in 1994-2004, Part I, Civil Engineering Journal 14 (3) (2005) 65-82, [In Czech].

[2] J. Witzany, V. Mencl, R. Wasserbauer, M. Gregerová, P. Pospíšil, T. Čejka, R. Zigler, E. Burgetová, Overall assessment of theoretical and experimental investigation of Charles Bridge in 1994-2004, Part II, Civil Engineering Journal 14 (4) (2005) 97-105, [In Czech].

[3] J. Witzany, R. Zigler, The analysis of non-stress effects on historical stone bridge structures (monitoring, theoretical analysis, maintenance), Journal of Civil Engineering and Management 13 (2) (2007) 157-167.

[4] J. Witzany, T. Cejka, Reliability and failure resistance of the stone bridge structure of Charles Bridge during floods, Journal of Civil Engineering and Management 13 (3) (2007) 227-236.

[5] L. Binda, G. Gatti, G. Mangano, C. Poggi, G. Sacchi Landriani, The collapse of the Civic Tower of Pavia: A survey of the materials and structure, Masonry International 6 (1) (1992) 11-20.

[6] P. Lourenço, Computations on historical masonry structures, Progress in Structural Engineering and Materials 4 (3) (2002) 301-319.

[7] M. Valluzzi, On the vulnerability of historical masonry structures: analysis and mitigation, Materials and Structures 40 (7) (2007) 723-743. 
[8] A. Giordano, E. Mele, A. De Luca, Modelling of historical masonry structures: Comparison of different approaches through a case study, Engineering Structures 24 (8) (2002) 1057-1069.

[9] P. Lourenço, Assessment, diagnosis and strengthening of Outeiro Church, Portugal, Construction and Building Materials 19 (8) (2005) 634-645.

[10] A. Carpinteri, S. Invernizzi, G. Lacidogna, In situ damage assessment and nonlinear modelling of a historical masonry tower, Engineering Structures 27 (3) (2005) 387-395.

[11] A. Carpinteri, S. Invernizzi, G. Lacidogna, Numerical assessment of three medieval masonry towers subjected to different loading conditions, Masonry International 19 (2) (2006) 65-76.

[12] P. Beran, J. Máca, The influence of temperature on the deformation of columns in the nave of Saint Vitus Cathedral at Prague Castle, Journal of Building Appraisal 2 (4) (2007) 313-322.

[13] P. Lourenço, K. Krakowiak, F. Fernandes, L. Ramos, Failure analysis of Monastery of Jeronimos, Lisbon: How to learn from sophisticated numerical models, Engineering Failure Analysis 14 (2) (2007) 280-300, papers presented at the 22nd meeting of the Spanish Fracture Group (Almargro, Spain, March 2005).

[14] H. G. Matthies, R. Niekamp, J. Steindorf, Algorithms for strong coupling procedures, Computer Methods in Applied Mechanics and Engineering 195 (1718) (2006) 2028-2049.

[15] T. Massart, R. Peerlings, M. Geers, An enhanced multi-scale approach for masonry wall computations with localization of damage, International Journal for Numerical Methods in Engineering 69 (5) (2007) 1022-1059.

[16] V. Hanzl, The photogrammetric measurement of Charles Bridge in Prague, International Archives of Photogrammetry, Remote Sensing and Spatial Information Sciences 34 (5) (2003) 183-184.

[17] D. Rypl, Sequential and parallel generation of unstructured 3D meshes, no. 3 in CTU Reports, Czech Technical University in Prague, 1998, http://mech. fsv.cvut.cz/ dr/t3d.html.

[18] V. Červenka, L. Jendele, J. Červenka, ATENA Program Documentation. Part 1: Theory, Červenka Consulting, Prague, http://www . cervenka.cz/Web (2005).

[19] V. Červenka, Simulating a response, Concrete Engineering International 4 (4) (2000) 45-49.

[20] V. Cervenka, Computer simulation of failure of concrete structures for practice, in: Proceedings of the first fib Congress 2002, Concrete Structures in the 21st Century, Osaka, Japan, 2002, pp. 289-304, available at http://www.cervenka. $\mathrm{cz} /$ papers 
[21] H. M. Künzel, Simultaneous heat and moisture transport in building components. One and two-dimensional calculation using simple parameters, Ph.D. thesis, Fraunhofer Institute of Building Physics,

http://www.hoki.ibp.fraunhofer.de/ibp/publikationen/
dissertationen/hk_dissertation_e.pdf (1995).

[22] R. Černý, P. Rovnaníková, Transport Processes in Concrete, Spon Press, 2002.

[23] J. Grunewald, DELPHIN 4.1-Documentation, theoretical fundamentals, TU Dresden.

[24] J. Maděra, Computer analysis of optimal thermal and moisture properties of materials and systems for interior thermal insulation of historical structures, Ph.D. thesis, Faculty of Civil Engineering, Czech Technical University in Prague, [In Czech] (2003).

[25] J. Záruba, P. Bouška, P. Štemberk, M. Vokáč, Measurement of non-force and aggressive environment effects of aging of historical structures with particular emphasis on Charles Bridge in Prague, Tech. Rep. 1302004, Klokner Institute, Czech Technical University in Prague, [In Czech] (2003).

[26] A. Anthoine, Derivation of the in-plane elastic characteristics of masonry through homogenization theory, International Journal of Solids and Structures 32 (2) (1995) 137-163.

[27] J. C. Michel, H. Moulinec, P. Suquet, Effective properties of composite materials with periodic microstructure: A computational approach, Computer Methods in Applied Mechanics and Engineering 172 (1999) 109-143.

[28] V. Kouznetsova, W. A. M. Brekelmans, P. T. Baaijens, An approach to micromacro modeling of heterogeneous materials, Computational Mechanics 27 (1) (2001) 37-48.

[29] J. Zeman, M. Šejnoha, From random microstructures to representative volume elements, Modelling and Simulation in Materials Science and Engineering 15 (4) (2007) S325-S335.

[30] T. Massart, R. Peerlings, M. Geers, Mesoscopic modeling of failure and damageinduced anisotropy in brick masonry, European Journal of Mechanics - A/Solids 23 (5) (2004) 719-735.

[31] C. Wu, H. Hao, Derivation of 3D masonry properties using numerical homogenization technique, International Journal for Numerical Methods in Engineering 66 (11) (2006) 1717-1737.

[32] J. Šejnoha, M. Šejnoha, J. Zeman, J. Sýkora, J. Vorel, A mesoscopic study on historic masonry, http://arxiv.org/abs/0804.3262 (2007).

[33] Z. Bittnar, J. Šejnoha, Numerical methods in structural mechanics, ASCE Press and Thomas Telford, Ltd, New York and London, 1996.

[34] J. Rímal, Charles Bridge in Prague - Measurements of moisture fields, International Journal for Restoration of Buildings and Monuments 10 (3) (2004) $237-250$. 
[35] R. Al-Khoury, L. Sluys, A computational model for fracturing porous media, International Journal for Numerical Methods in Engineering 70 (4) (2007) 423444 .

[36] P. Grassl, C. Pearce, Discrete modelling of fracture and moisture transport in heterogeneous materials, in: M. Jirásek, Z. Bittnar, H. Mang (Eds.), MHM 2007: Modelling of Heterogeneous Materials with Applications in Construction and Biomedical Engineering, CTU Publishing House, Prague, 2007, pp. 138-139.

[37] J. Rethore, R. de Borst, M. Abellan, A two-scale approach for fluid flow in fractured porous media, International Journal for Numerical Methods in Engineering 71 (7) (2007) 780-800.

[38] I. Özdemir, W. A. M. Brekelmans, M. G. D. Geers, Computational homogenization for heat conduction in heterogeneous solids, International Journal for Numerical Methods in Engineering 73 (2) (2008) 185-204.

[39] J. Sýkora, J. Vorel, T. Krejčí, M. Šejnoha, J. Šejnoha, Analysis of coupled heat and moisture transfer in masonry structures, http://arxiv.org/abs/0804. 3554 (2007).

[40] J. Římal, Charles Bridge in Prague - Measurements of temperature fields, International Journal for Restoration of Buildings and Monuments 9 (6) (2003) $585-602$.

[41] ČSN 73 6503, Hydrostatic pressure load of water system structures, Czech Standards Institute (1979).

[42] F. Čihák, L. Satrapa, P. Fošumpaur, Assesment of flow profiles between piers of Charles Bridge in Prague during 2002 flood, Tech. rep., Czech Technical University in Prague, [In Czech] (2004).

[43] J. Šejnoha, J. Zeman, J. Novák, M. Šejnoha, Simulation of a floating bay impact on Charles Bridge in Prague during flood, Civil Engineering Journal 15 (3) (2006) 65-69, [In Czech].

[44] D. Proske, M. Curbach, Risk to historical bridges due to ship impact on German inland waterways, Reliability Engineering \& System Safety 90 (2-3) (2005) 261270 .

[45] P. Roca, C. Molins, Dynamic load tests on masonry structures as inspection technique, in: Inspection and Monitoring of the Architectural Heritage, Italian Group of International Association for Bridge and Structural Engineering, Ferrari Editrice, 1997, pp. 133-140.

[46] ČSN EN 1997-1, Eurocode 7: Geotechnical design - Part 1: General rules, Czech Standards Institute (2006).

[47] ČSN 73 6220, Loading capacity and register of road bridges, Czech Standards Institute (1996). 


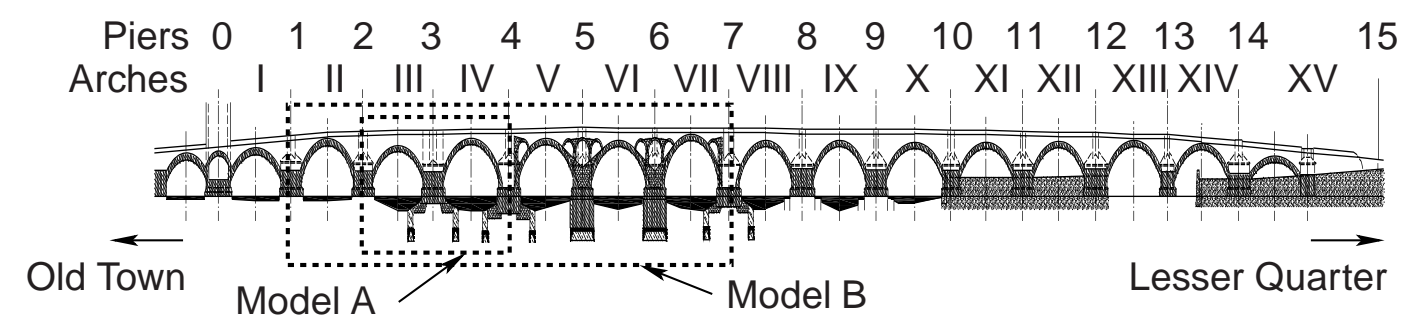

(a)

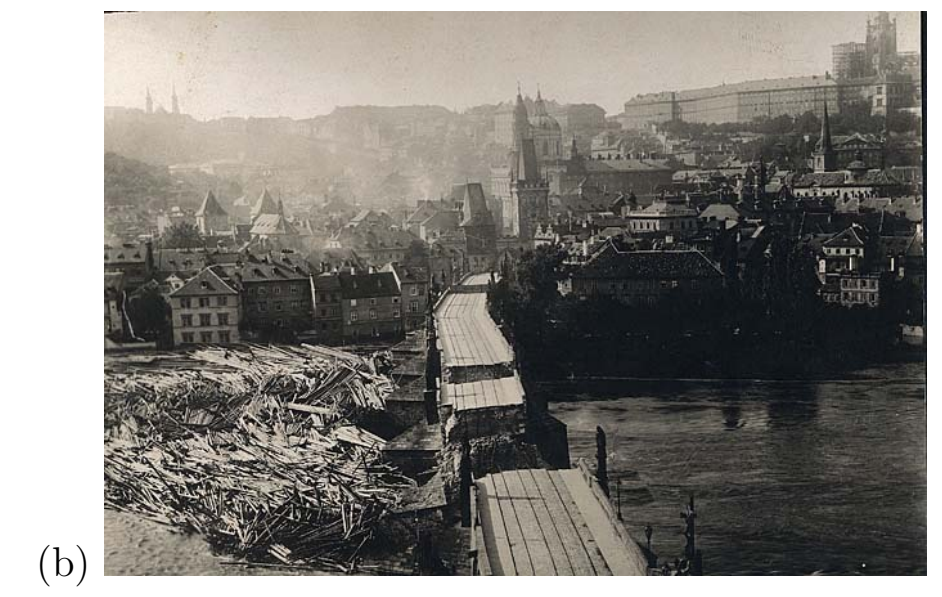

Fig. 1. Charles Bridge in Prague; (a) scheme of the structure, (b) the 1890 flood (Courtesy of the Society for Old Prague).

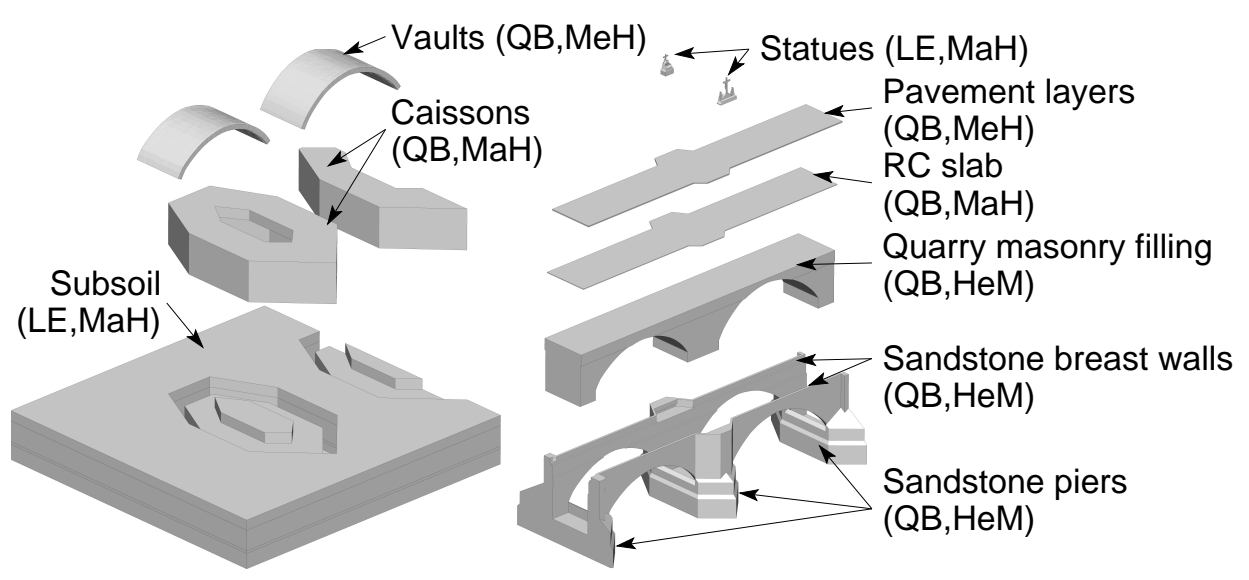

Fig. 2. Exploded view of a CAD model of the bridge; LE - linear elastic, QB quasi-brittle material models, $\mathrm{MaH}$ - macroscopically homogeneous, $\mathrm{MeH}$ - mesoscopically homogeneous units. 


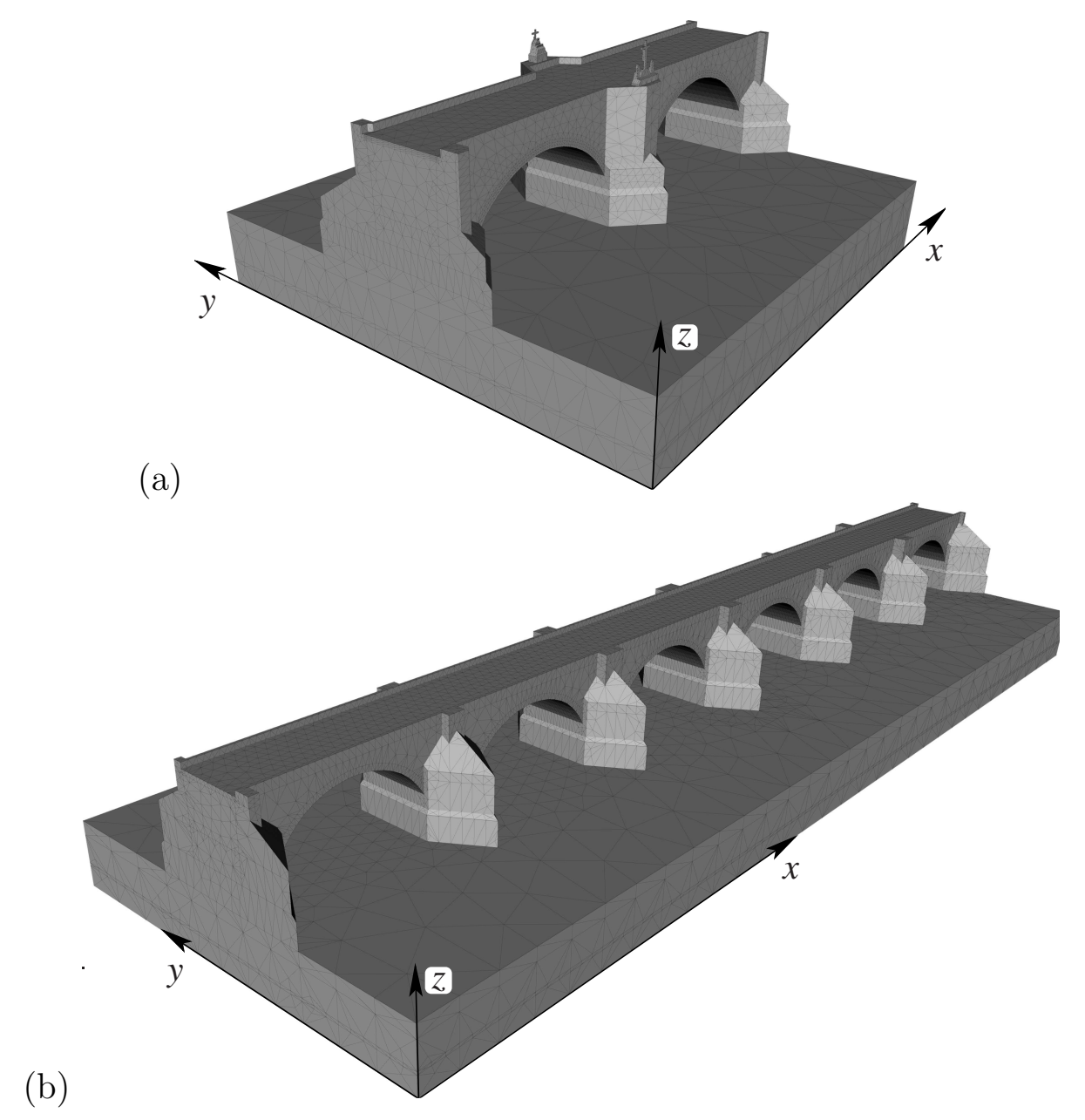

Fig. 3. Tetrahedral finite element meshes; (a) two-span and (b) six-span segments.

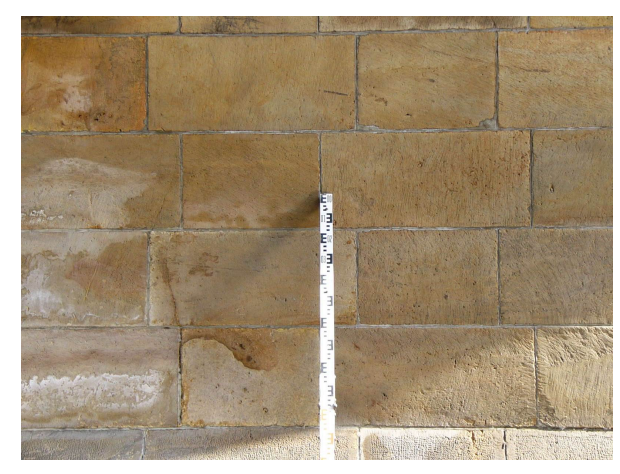

(a)

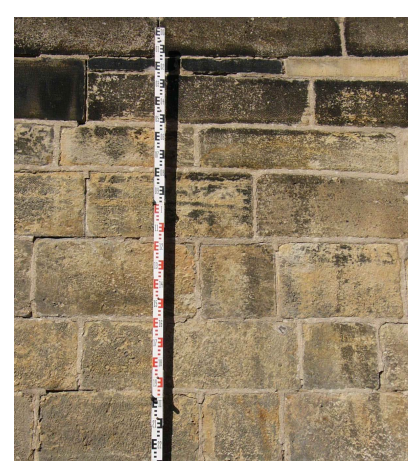

(b)

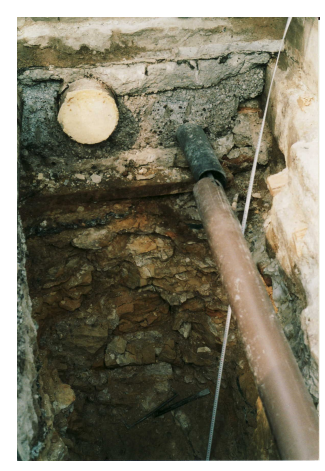

(c)

Fig. 4. Typical mesoscopic heterogeneity patterns; (a) regular periodic masonry, (b) non-periodic texture, (c) disordered masonry filling. 
(a)

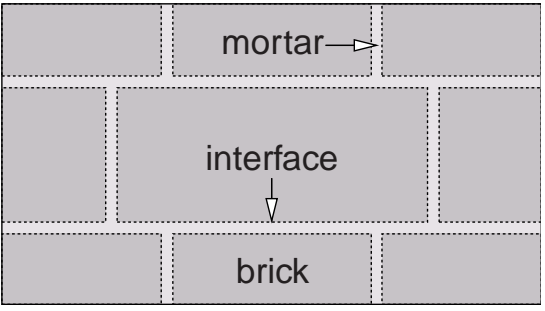

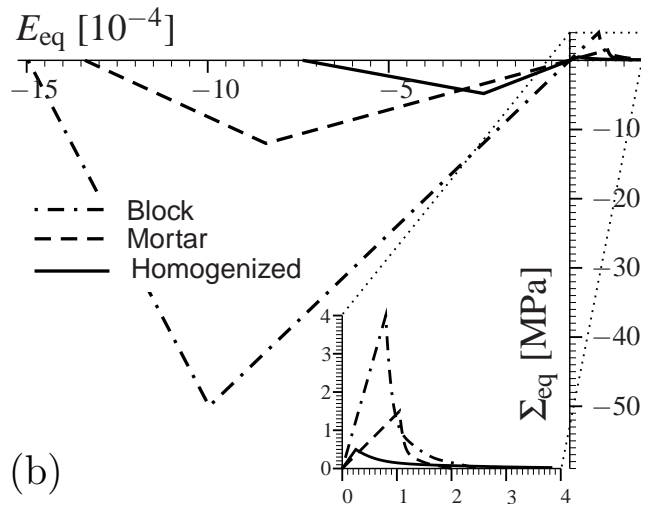

Fig. 5. Homogenization of periodic sandstone masonry; (a) scheme of the periodic unit cell, (b) examples of resulting stress-strain diagrams; the characteristic length in tension and compression is $1 \mathrm{~m}$.
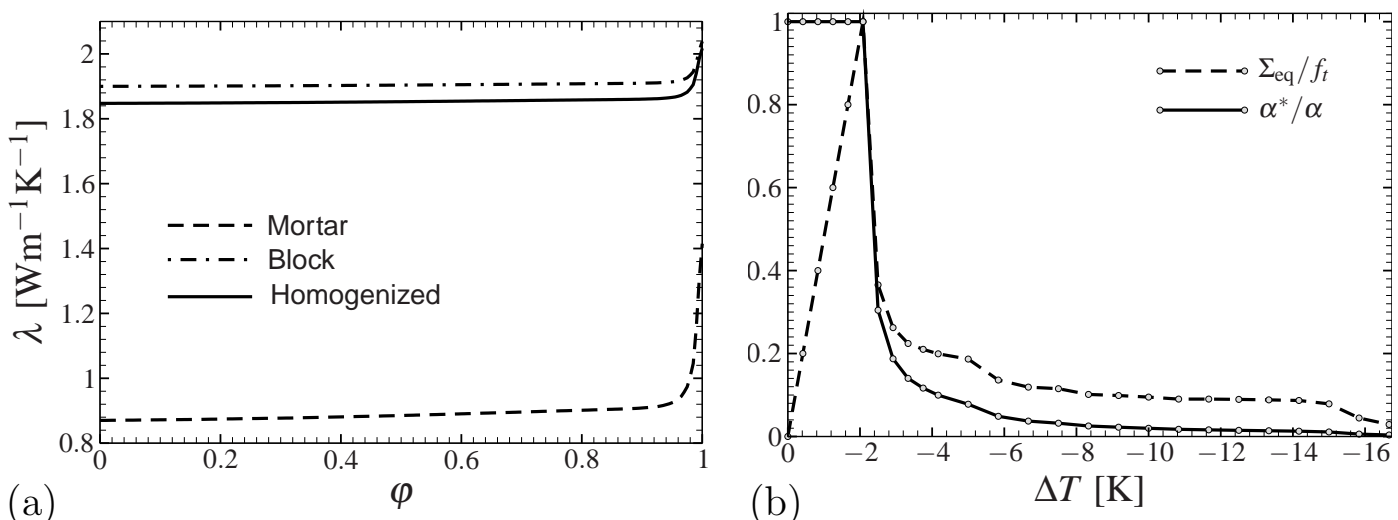

Fig. 6. Examples of thermo-mechanical homogenization analysis; effective (a) thermal conductivities as functions of relative humidity $\varphi$, (b) coefficients of thermal expansion.

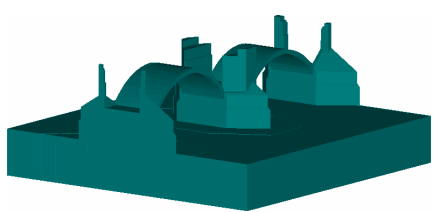

(a)

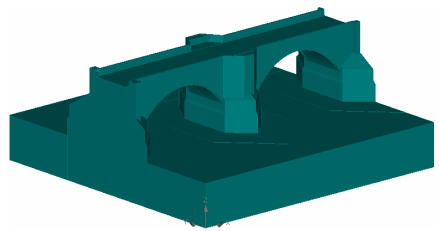

(b)

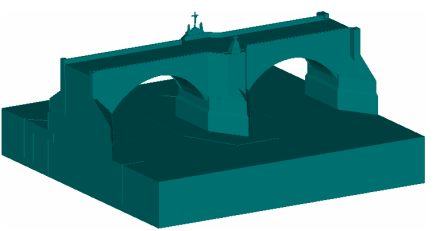

(c)

Fig. 7. Simulation of the construction sequence; (a) piers and vaults, (b) breast walls and bridge filling, (c) pavement including concrete slab and statues. 


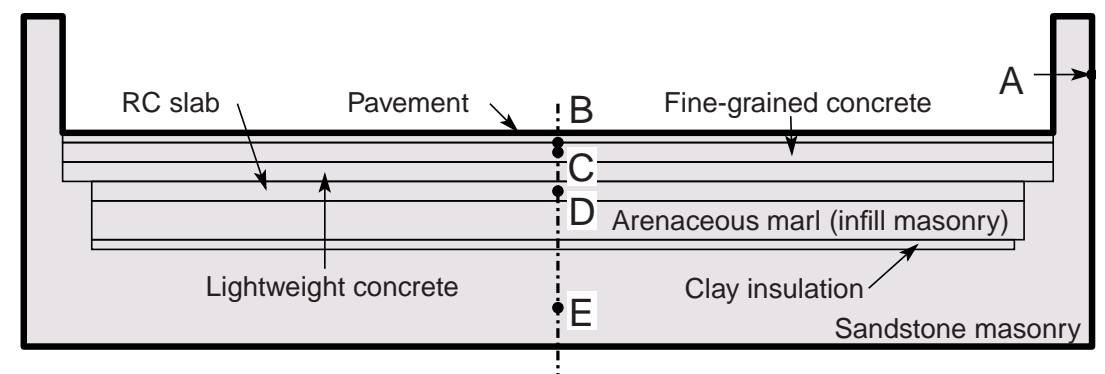

Fig. 8. Analyzed cross-section of the bridge and location of monitoring points.
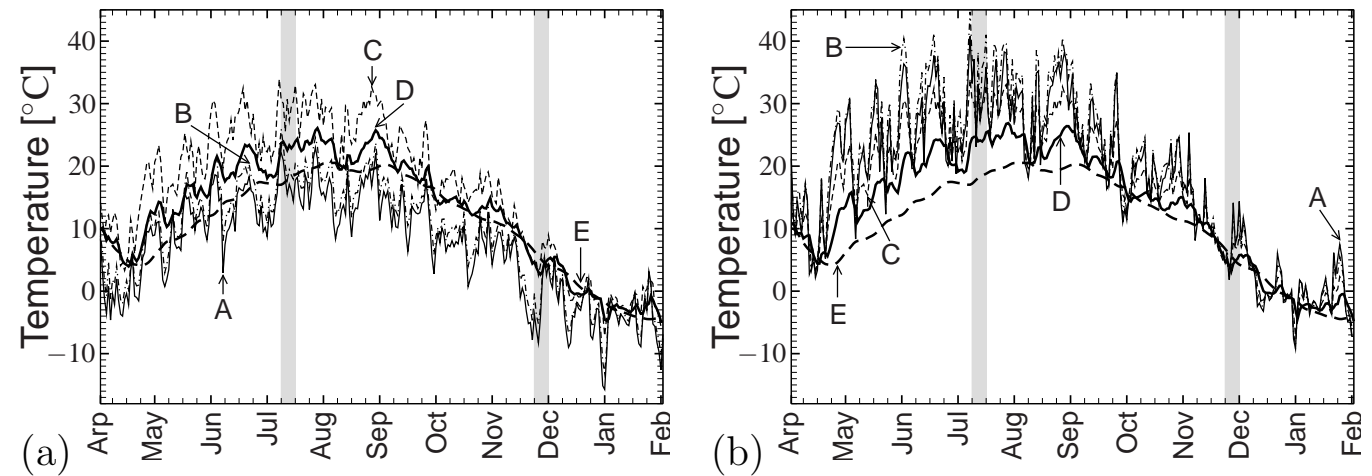

Fig. 9. Results of transient simulations; distribution of daily (a) minimum (b) maximum temperatures. 


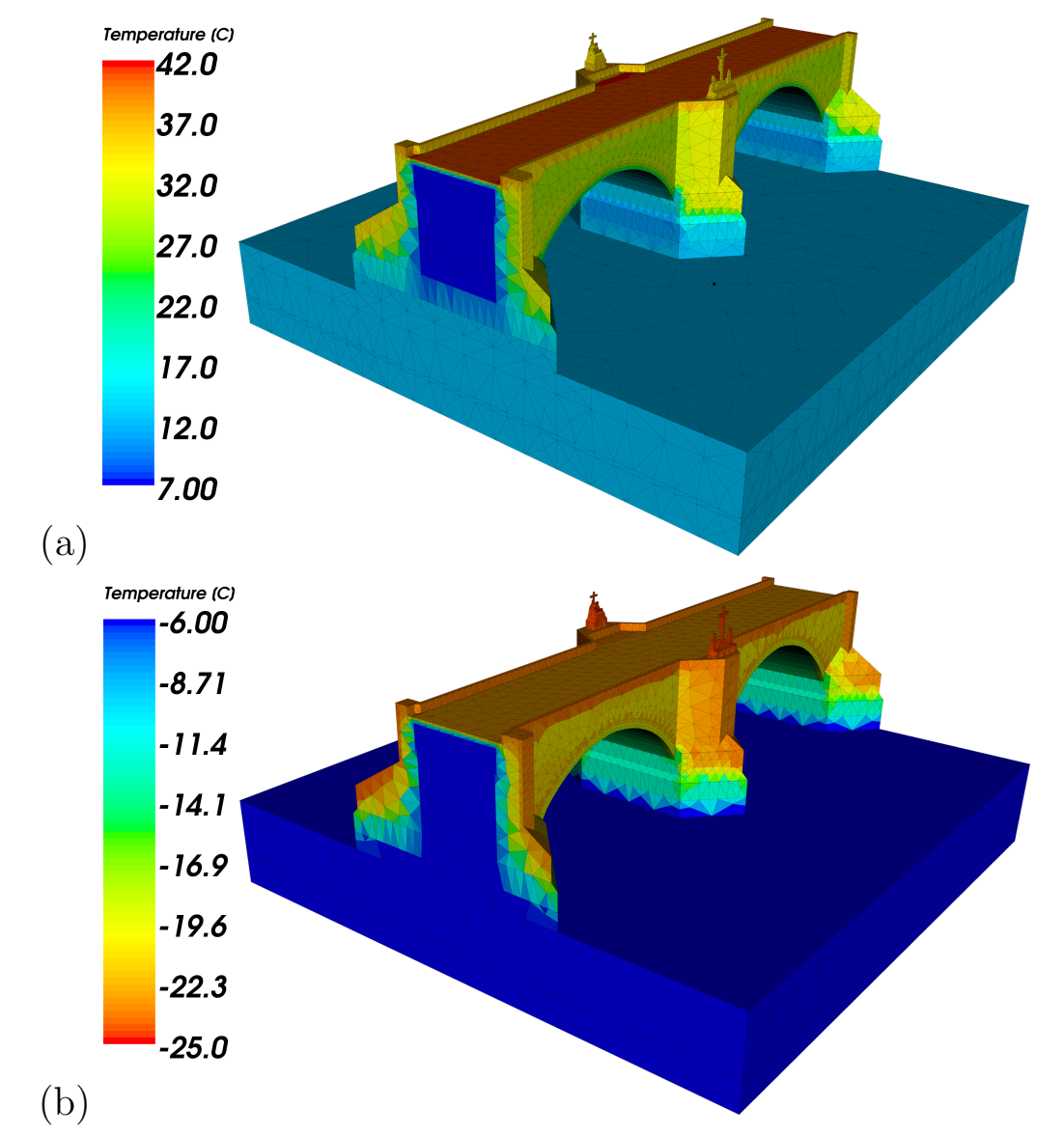

Fig. 10. Distribution of extreme temperature changes; (a) summer, (b) winter.

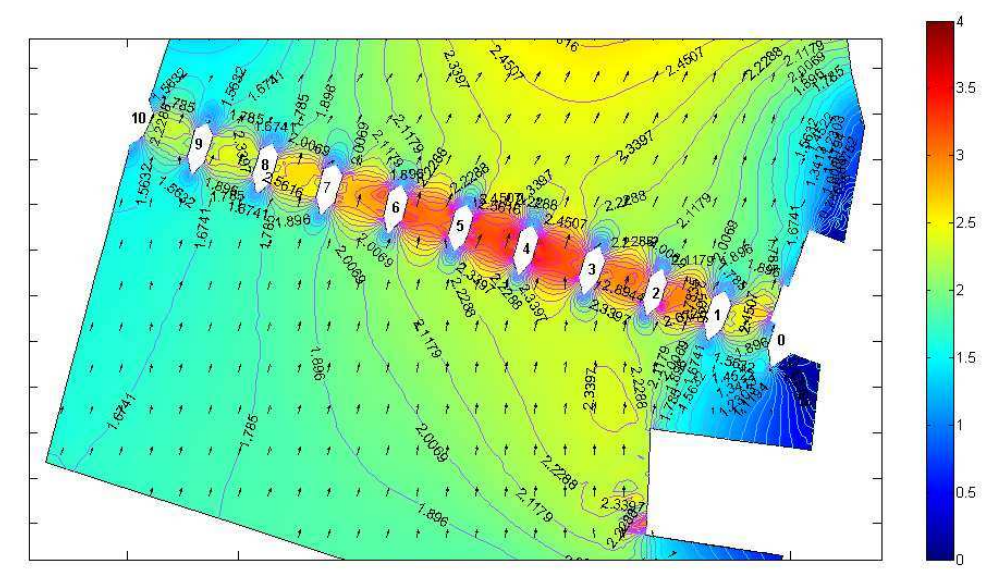

Fig. 11. Velocity profiles during the 2002 flood (Courtesy of F. Čihák, CTU in Prague). 


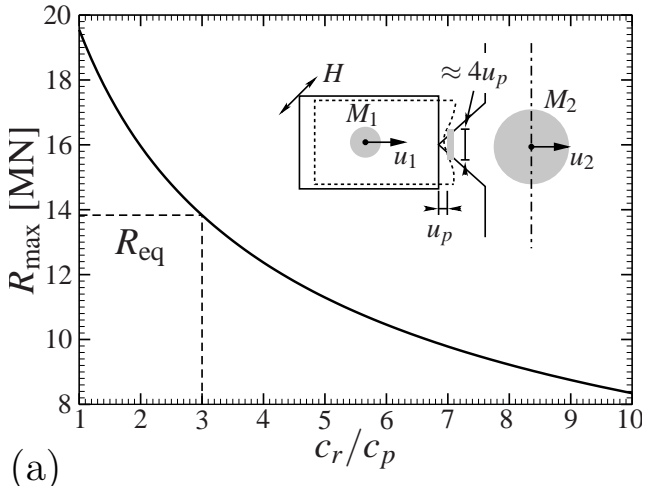

(a)

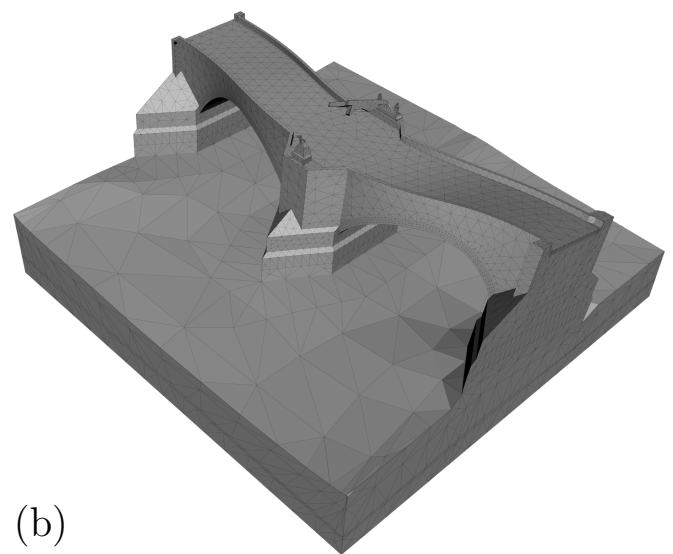

Fig. 12. Impact simulation; (a) contact force and scheme of bridge impact, (b) dominant eigenmode $\left(\omega_{2}=20.1 \mathrm{~Hz}\right)$; segment is rotated for visualization purposes.

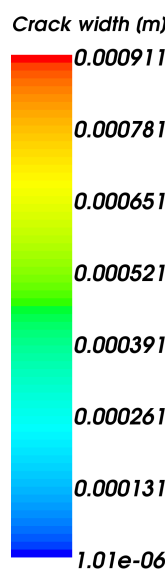

(a)

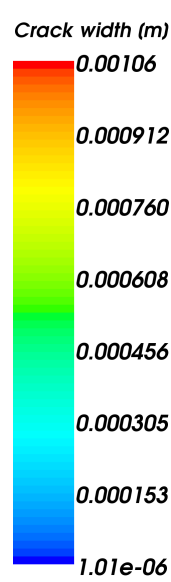

(b)

Fig. 13. Crack width distribution due to temperature change; self-weight $(\gamma=1.1$, $\psi=1) \oplus$ normal water level $(\gamma=1.4, \psi=1) \oplus$ (a) summer temperature change $(\gamma=1, \psi=1),(\mathrm{b})$ winter temperature change $(\gamma=1, \psi=1)$. 

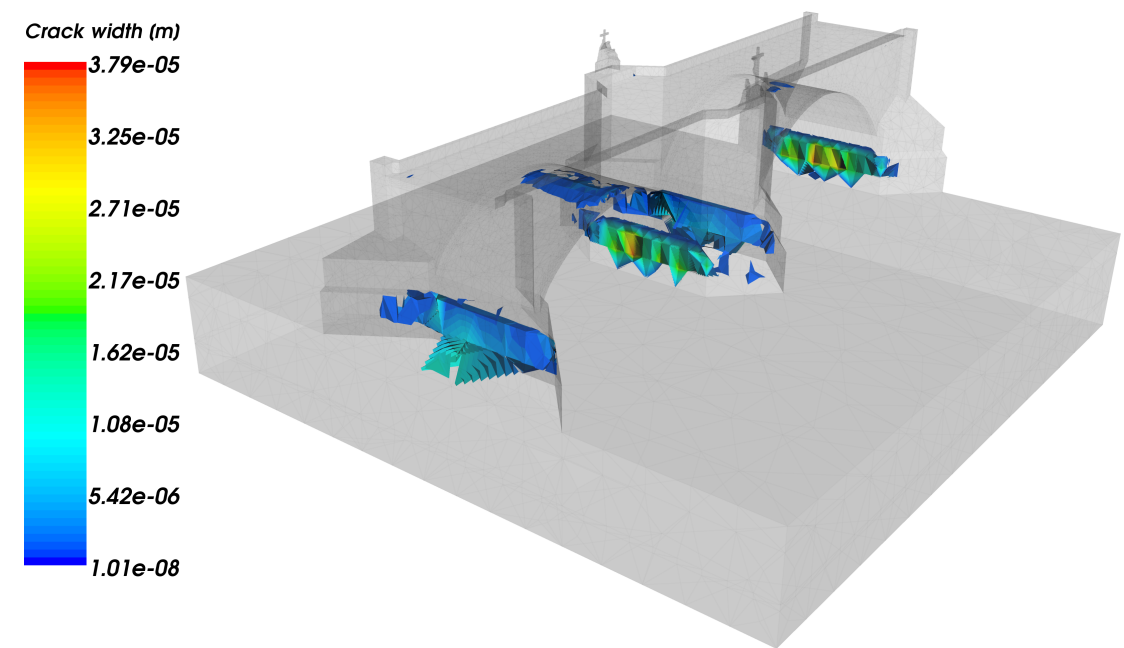

Fig. 14. Crack width distribution due to temperature cycle; self-weight $(\gamma=1.1$, $\psi=1) \oplus$ normal water level $(\gamma=1.4, \psi=1) \oplus$ summer temperature change $(\gamma=1, \psi=0.6) \oplus$ winter temperature change $(\gamma=1, \psi=0.6)$. 


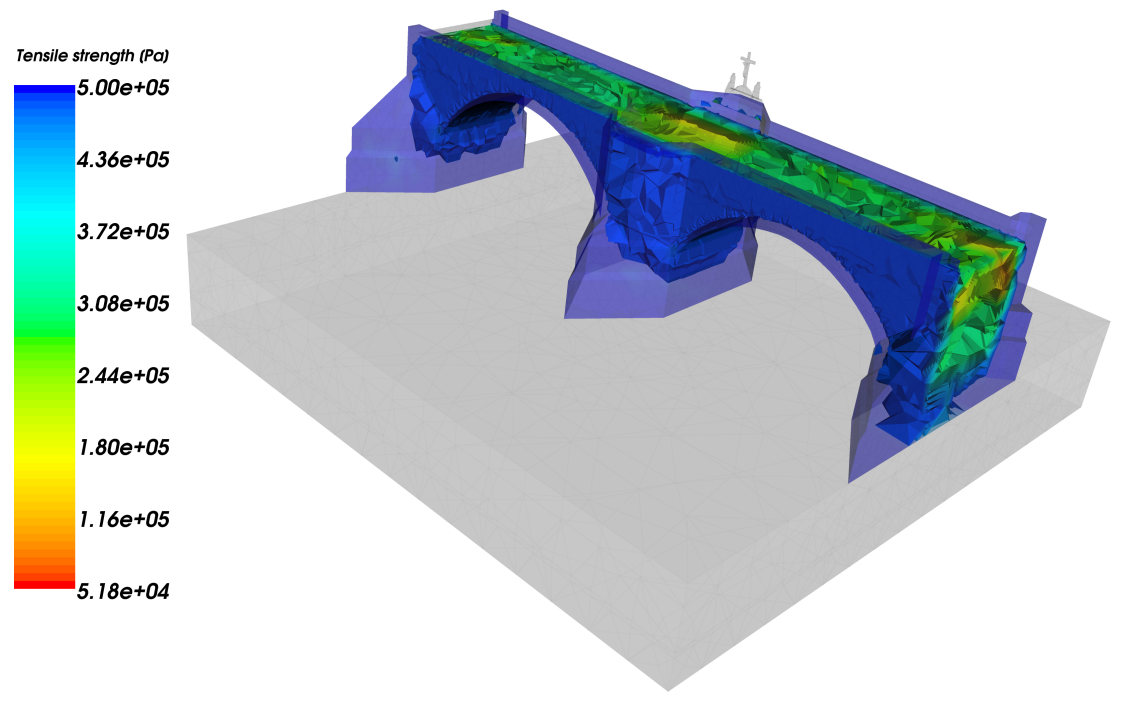

(a)

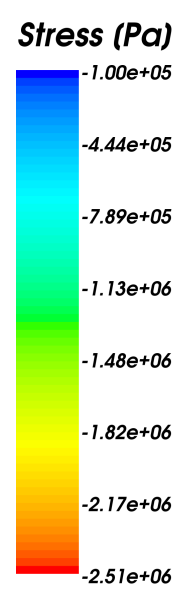

(b)

Fig. 15. Floating vessel impact during flood; self-weight $(\gamma=0.9, \psi=1) \oplus$ flood water level $(\gamma=1.4, \psi=0.6) \oplus$ summer temperature change $(\gamma=1, \psi=0.6) \oplus$ vehicle $(\gamma=1, \psi=1)$; distribution of (a) residual tensile strength $f_{t}$, (b) stress $\sigma_{y y}$ field; segment is rotated for visualization purposes. 


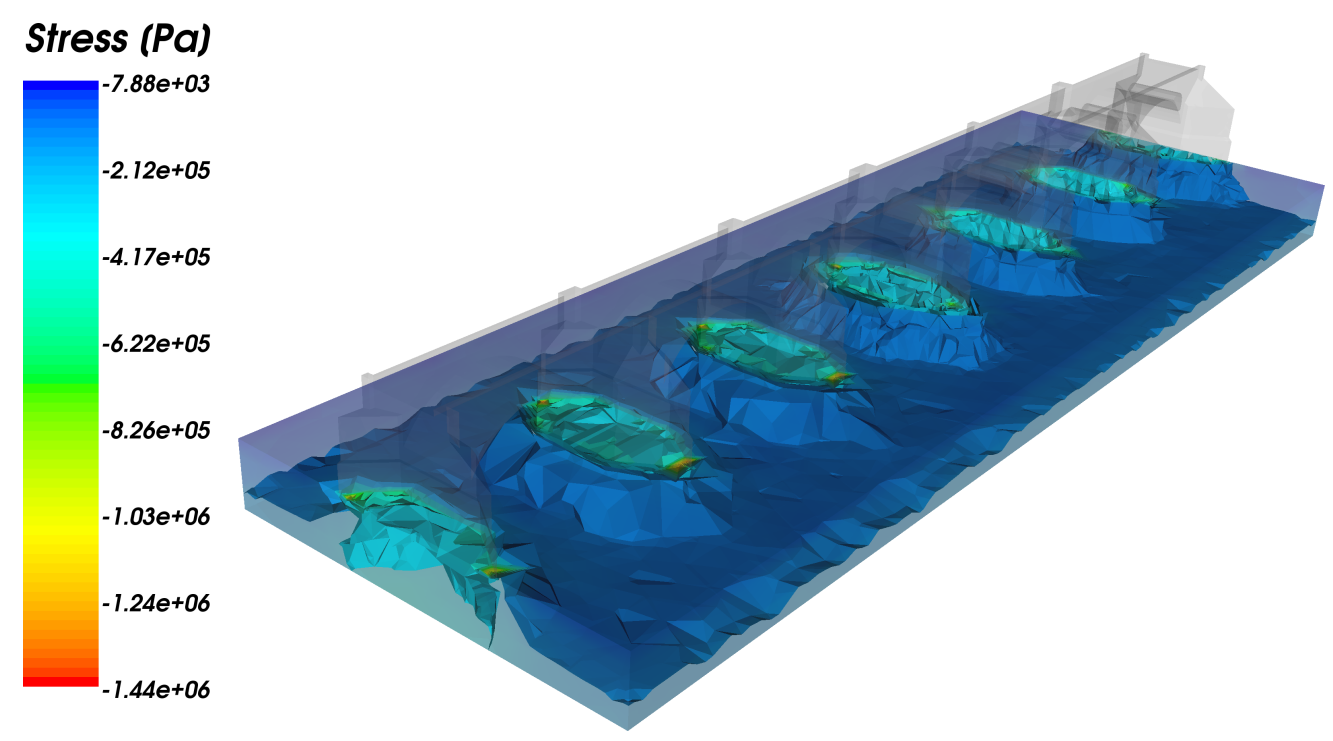

Fig. 16. Distribution of the $\sigma_{z z}$ stress field in subsoil; self-weight $(\gamma=1.1, \psi=1)$ $\oplus$ normal water level $(\gamma=1.4, \psi=0.6)$.

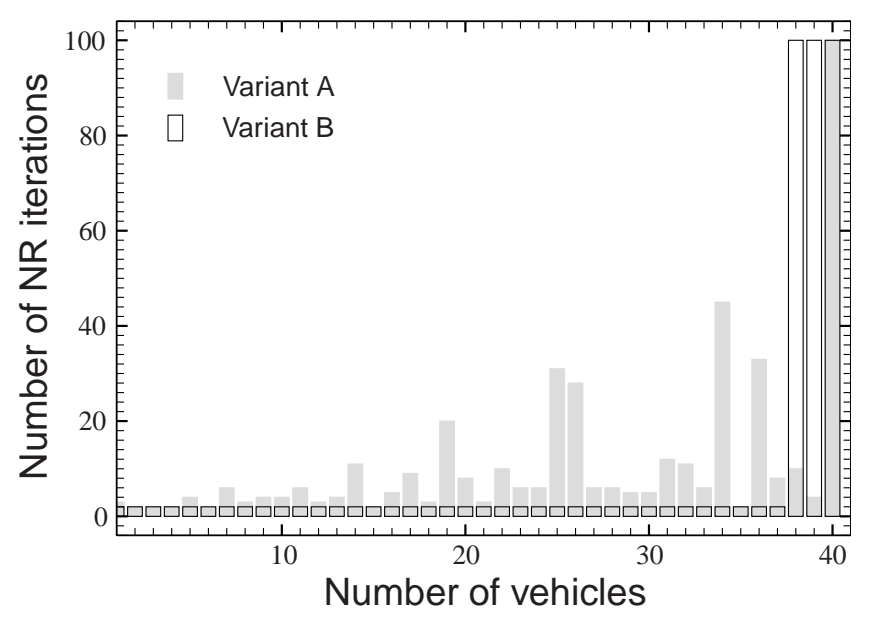

Fig. 17. Convergence plots used to estimate the load-bearing capacity. 


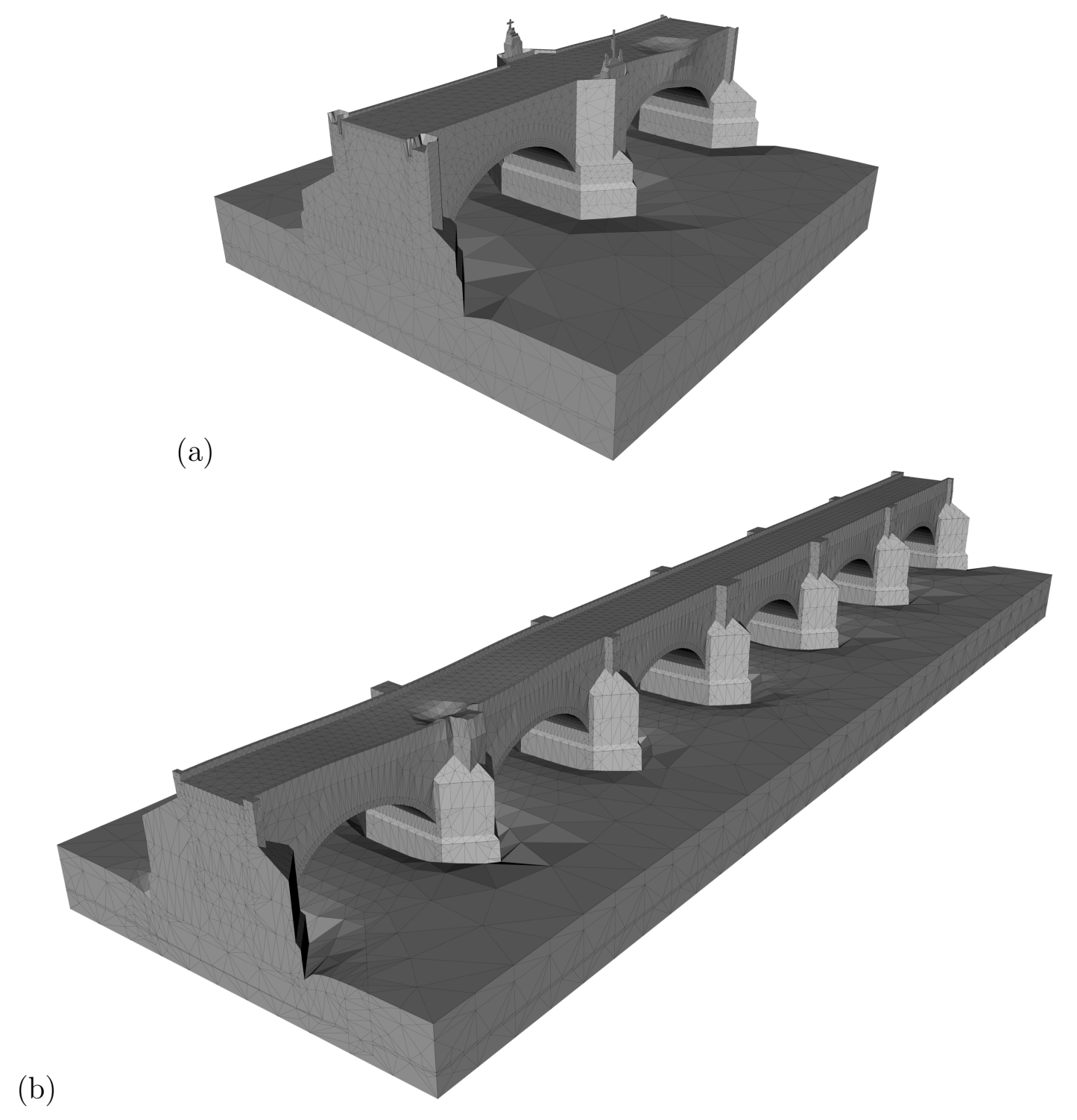

Fig. 18. Ultimate bridge failure mode; (a) Model A, (b) Model B; displacements are scaled by a factor of 200 . 


\begin{tabular}{|c|c|c|c|c|c|}
\hline 1406 & \multicolumn{5}{|l|}{ Completion of Charles Bridge } \\
\hline 1432 & \multicolumn{5}{|c|}{ Damage due to flood, piers No. $3,4,7,8,10$} \\
\hline 1496 & \multicolumn{5}{|c|}{ Erosion by the flow of water and pier No. 3 drop } \\
\hline till 1503 & \multicolumn{5}{|c|}{ Repair of damage from years 1432 and 1496} \\
\hline 1655 & \multicolumn{5}{|l|}{ Damage to pier foundations } \\
\hline 1784 & \multicolumn{5}{|c|}{ Damage to the foundation of three piers and five vaults } \\
\hline till 1788 & \multicolumn{5}{|c|}{ Repair of damage from year 1784} \\
\hline 1890 & \multicolumn{5}{|c|}{ Vaults No. 5,6 and 7 destroyed, piers No. 4, 8 damaged (Fig. 1(b)) } \\
\hline 1893 & \multicolumn{5}{|c|}{ Repair of damage from year 1890} \\
\hline 1903 & \multicolumn{5}{|c|}{ Rehabilitation of piers No. 3,4 and 7} \\
\hline $1966-1975$ & \multicolumn{5}{|c|}{ Major reconstruction, grouting, reinforced concrete slab installed, } \\
\hline 2002 & \multicolumn{5}{|c|}{ More than 100-year flood, the bridge survived } \\
\hline $2004-2005$ & \multicolumn{5}{|c|}{ Strengthening of foundations (Piers No. 8 and 9) } \\
\hline \multicolumn{6}{|c|}{$\begin{array}{l}\text { Table } 1 \\
\text { Brief history of Charles Bridge damage and repairs. }\end{array}$} \\
\hline \multirow[t]{2}{*}{ Parameter } & & Block & Mortar & Interface & Homogenized \\
\hline & & {$[25]$} & {$[25]$} & {$[32]$} & \\
\hline \multicolumn{2}{|c|}{ Young's modulus, $E$ [GPa] } & 50.2 & 14.3 & $\times$ & 20.2 \\
\hline \multicolumn{2}{|c|}{ Possion's ratio, $\nu[-]$} & 0.15 & 0.18 & $\times$ & 0.15 \\
\hline \multicolumn{2}{|c|}{ Cohesion, $c[\mathrm{MPa}]$} & $x$ & $\times$ & 0.13 & $x$ \\
\hline \multicolumn{2}{|c|}{ Angle of internal friction, $\phi\left[^{\circ}\right]$} & $\times$ & $\times$ & 17.0 & $\times$ \\
\hline \multicolumn{2}{|c|}{ Tensile strength, $f_{t}[\mathrm{MPa}]$} & 4.0 & 1.5 & 0.1 & 0.5 \\
\hline \multicolumn{2}{|c|}{ Compressive strength, $f_{c}[\mathrm{MPa}]$} & 50.0 & 12.0 & $\times$ & 4.8 \\
\hline \multicolumn{2}{|c|}{ Fracture energy, $G_{f}\left[\mathrm{Nm}^{-1}\right]$} & 80.0 & 20.0 & $x$ & 35 \\
\hline \multicolumn{2}{|c|}{ Limit compressive crack opening, $w_{d}[\mathrm{~m}]$} & $5 \cdot 10^{-4}$ & $5 \cdot 10^{-4}$ & $x$ & $5 \cdot 10^{-4}$ \\
\hline \multicolumn{2}{|c|}{ Volume fraction [\%] } & 97.5 & 2.5 & 0 & 100 \\
\hline
\end{tabular}

Selected material constants for the mechanical constitutive model. 


\begin{tabular}{lrrr}
\hline Parameter & Block & Mortar & Homogenized \\
& {$[23,24]$} & {$[23,24]$} & \\
\hline Density, $\rho\left[\mathrm{kgm}^{-3}\right]$ & 1964 & 1700 & 1957 \\
Thermal conductivity, $\lambda\left[\mathrm{Wm}^{-1} \mathrm{~K}^{-1}\right]$ & 1.9 & 0.87 & 1.86 \\
Heat capacity, $c\left[\mathrm{Jkg}^{-1} \mathrm{~K}^{-1}\right]$ & 900 & 1000 & 903 \\
Thermal expansion coefficient, $\alpha\left[10^{-6} \mathrm{~K}^{-1}\right]$ & 12 & 12 & 7 \\
\hline
\end{tabular}

Table 3

Selected material constants for the transport constitutive model.

\begin{tabular}{lrrrr}
\hline Measurement point & \multicolumn{2}{c}{ July } & \multicolumn{2}{c}{ November } \\
Temperature $\left[{ }^{\circ} \mathrm{C}\right]$ & Experiment $[40]$ & Simulation & Experiment $[40]$ & Simulation \\
\hline $\mathrm{B}$ & $24 \div 40$ & $17.8 \div 38.2$ & $-3 \div-6$ & $-5.2 \div 9.1$ \\
$\mathrm{C}$ & $26 \div 34$ & $20.5 \div 30.9$ & $-1 \div-3$ & $-1.0 \div 7.6$ \\
$\mathrm{D}$ & $21 \div 22$ & $22.5 \div 24.7$ & $2 \div 3$ & $2.6 \div 8.2$ \\
$\mathrm{E}$ & $18 \div 19$ & $17.0 \div 18.6$ & $4 \div 5$ & $5.3 \div 8.0$ \\
\hline
\end{tabular}

Table 4

Validation of heat transfer simulations.

\begin{tabular}{lr}
\cline { 2 - 2 } Mass of tag boat, $M_{1}$ & $2,300 \mathrm{ton}$ \\
Effective vibrating mass of bridge, $M_{2}$ & $9,200 \mathrm{ton}$ \\
Height of the contact area, $H$ & $1.36 \mathrm{~m}$ \\
Compressive strength of pier, $f_{c}$ & $4.8 \mathrm{MPa}$ \\
Initial boat velocity, $v_{r}$ & $3.5 \mathrm{~ms}^{-1}$ \\
Relevant bridge eigenfrequency, $\omega_{2}$ & $20.1 \mathrm{~Hz}$ \\
\hline
\end{tabular}

Table 5

Parameters of impact model.

\begin{tabular}{lrrrr}
\hline Quantity & \multicolumn{3}{r}{ Summer season } & Winter season \\
& Exp. [2,3] & Simul. & Exp. [2,3] & Simul. \\
\hline Horizontal displ. of breast walls $[\mathrm{mm}]$ & $-0.25 \pm 2.75$ & $-0.07 \pm 3.12$ & \pm 2 & $0.04 \pm 1.62$ \\
Vertical displ. of breast walls $[\mathrm{mm}]$ & $-0.5 \pm 3.5$ & $-0.8 \pm 3.18$ & \pm 1.5 & $0.44 \pm 1.87$ \\
Tilt of breast walls [mrad] & $16 \pm 48$ & $5.39 \pm 64.13$ & \pm 73 & $-2.01 \pm 63.73$ \\
Crack width on bridge vault $[\mu \mathrm{m}]$ & $310 \pm 110$ & $220(35)$ & $550 \pm 150$ & $524(53)$ \\
\hline
\end{tabular}

Table 6

Validation of non-linear mechanical model. 